\title{
Reprodução, Partos, Maternidades e Paternidades: Perspectivas Contemporâneas em Antropologia e Saúde
}

A maternidade compulsória e a naturalização do amor materno enquanto instintivo são alguns dos papéis atribuídos às mulheres a partir da modernidade (BADINTER, 1985). No mesmo sentido, passaram a emergir uma série de normas, condutas e imposições sobre o corpo da mulher, que encontraram no campo científico seu instrumento legitimador, sendo a dinâmica dos sistemas de saúde e da própria ciência construídas segundo a dinâmica das relações de gênero impostas na sociedade. A ginecologia e a obstetrícia, enquanto campos da ciência e prática de cuidado com a saúde e o corpo, são parte da diferenciação de sexos e de gêneros, e, desde o século XIX, atuam desde uma materialização e "substancialização da diferença" (ROHDEN, 2001, p. 13). Portanto, além das mulheres serem compelidas a conduzirem suas vidas em conformidade com a ordem namorar, casar e ter filhos, quando elas os têm, ainda enfrentam uma série de desafios, os quais buscamos abordar e visibilizar neste número especial sobre Reprodução, Partos, Maternidades e Paternidades.

As temáticas trazidas nessa publicação tem ganhado cada vez mais espaço na arena pública, nos meios de comunicação, nas redes sociais e em grupos e sites específicos que se formam para discutir e atuar em torno do parto, maternidade e paternidade em suas várias dimensões; além de uma efervescência das discussões e organização política, principalmente de mulheres, visando a elaboração de leis e de políticas públicas. O campo das ciências não fica de fora e, dessa maneira, consideramos importante tratar aqui, mesmo que como um sobrevoo, as características e as principais transformações dos estudos sobre reprodução, partos, maternidades e paternidades, com foco na produção de uma antropologia que dialoga com as áreas da saúde.

Nesse campo específico, bastante atual dentro da antropologia, muitas são as antropólogas que iniciam suas investigações desde suas trajetórias políticas e pessoais, e não raro, desde suas trajetórias reprodutivas. Sejam estas experiências positivas ou de violências e/ou de agravos aos direitos sexuais e reprodutivos. Uma espécie de movimento, abordado por Rosamaria Giatti e Fernanda Bittencourt (2015), de desdobramento do "pessoal é político" em o "pessoal é acadêmico ou científico”. 
As acadêmicas feministas brasileiras, na década de 1980, estavam centradas em fazer uma articulação entre trabalho acadêmico especializado e preocupações de intervenção social através de políticas públicas de correção de desigualdades sociais. O feminismo em geral, e também na América Latina e Brasil, baseava-se na construção de um modelo de feminilidade que relativizava a maternidade como ideal exclusivo e constitutivo das mulheres. Aqui vemos influências das ideias sobre "sistemas de sexo-gênero" de Gayle Rubin (1993), de outras teóricas e ativistas, centradas na afirmação da reprodução como elemento estruturador de significados e de posições sociais e de diferenças.

Ao abordar questões acerca da reprodução, as feministas deste período, em sua maioria brancas de camadas médias, estavam muito mais inclinadas ao tema do aborto, depois das tecnologias reprodutivas, ou até mesmo do parentesco, do que aos temas de partos, nascimentos e maternidades. Reconhecemos a importância histórica, política, teórica e contextual destas reflexões e destas mulheres, ainda que, nos somemos às críticas de feministas e mulheristas negras e de antropólogas como Aída Hernandéz Castillo e Liliana Navaz (2008) que chamam atenção para a crítica das feministas hegemônicas ao maternalismo como uma tensão entre paradigmas e interesses de mulheres brancas e não brancas. Aqui recordamos ativistas negras da Bahia e a antropóloga Rita Laura Segato (2006) que falam sobre a negação às mulheres negras da experiência da maternidade.

Desde o ano de 1996 é possível falar de uma gama de trabalhos de mulheres pesquisadoras que abordam questões em torno do parto, maternidades, e depois paternidades, a partir de diversas perspectivas e com temáticas que variam entre assistência, ciência e tecnologia, humanização, violência, relações de poder, parto domiciliar e parto hospitalar, parteria tradicional, formação de profissionais de saúde, as transformações que ocorrem a partir da popularização da internet e das redes sociais.

Avaliamos que é importante pontuar que acercar-se do tema dos partos, nascimentos e maternidades pode e tem significado a abertura de outras janelas para compreensão das sociedades, ao repensar questões caras para a antropologia e para o feminismo, tais quais as tensões ao redor do mito do amor materno, maternidades contemporâneas, maternidades lésbicas, transparentalidades, dinâmicas dos novos movimentos políticos e novos feminismos, a internet como arena política 
e de organização de movimentos de mulheres, relações de gênero, saberes, modelo médico, mercado, consumo, concepção de mulher e de homem e/ou masculinidades e paternidades, cuidado de si, processos de subjetivação, antropologia das emoções, biopolítica, farmacopoder, políticas dos corpos, noção de pessoa, religião, ciência, tecnologias, natureza/cultura, tradição.

Sobre o tema da tradição, é possível acompanhar o surgimento de cada vez mais trabalhos sobre parteiras e partos tradicionais, em geral indígenas. Todavia, pensamos que, especificamente dentro do que algumas antropólogas tem chamando de Antropologia dos Partos, Nascimentos e Maternidades, ainda falte maior profundidade na reflexão sobre parterias, parteiras e partos ditos tradicionais e as transformações nos padrões de parto no Brasil, de forma que ultrapasse o contexto de comunidades e da etnologia indígena.

Um pontapé para o início dos estudos sobre partos e maternidades dentro da antropologia e talvez das ciências sociais, e até mesmo uma parte dos esforços dentro da área da saúde, tem sido considerar as experiências reprodutivas das mulheres que já são ou se tornam ativistas e pesquisadoras deste tema, as nossas experiências. Vivemos um período de influência da discussão sobre lugar de fala e a importância de refletir social e politicamente desde si mesma, a crescente consolidação de movimentos de mulheres que se organizam em torno das questões ligadas à reprodução, mas, com foco na gravidez, parto, puerpério e maternidades; e esse movimento faz um chamado para olharmos para a violência específica a que são submetidas as mulheres (e também suas famílias contíguas) durante este período, com ênfase nas experiências de parto, o que agora é nomeado de violência obstétrica.

Hoje, o simples ato de nomear, para além de alerta coletivo e da possibilidade das mulheres nomearem o que vivem e as dores que sentem, se constitui como uma ação política de enfrentamento importante, pois a partir disso temos visto crescer no país as denúncias e processos envolvendo violência obstétrica, bem como incipientes tentativas de elaboração e execução de políticas públicas ou projetos de leis; além do mais, a própria reação dos médicos obstetras, e do novo governo e do ministério da saúde, apoiados por setores mais conservadores das associações e conselhos de medicina, em tentar apagar o termo por decreto, demonstra a potencialidade do ato de nomear a violência obstétrica e afirmá-la como mais um tipo de violência 
de gênero e misógina. E é fundamental ressaltar que os dados de pesquisas mais recentes nos revela que as mulheres mais afetadas por esta violência são as mulheres negras e indígenas, em um continuum desde Anarcha, Betsy e Lucy.

Considerando os números altíssimos de mortes e morbidades materno-infantis, as violações de direitos humanos das mulheres, as mutilações diárias a que estão submetidas em contextos hospitalares no Brasil com a prática rotineira da episiotomia, o que faz com que muitas delas recorram às experiências de estupros ou a ideia de campo de concentração para descrever suas experiências de parto, como afirmou Ligia Moreiras Sena (2016) em sua tese, não há como uma antropologia e um movimento que se reivindicam feministas ignorar ou tratar estes temas como de segunda ordem.

Em suma, é em uma conjuntura teórica e política que dá importância para o movimento de olhar e refletir sobre nossas próprias experiências, pensar desde nossos lugares de fala e produzir ciência cada vez mais situada e que faça uso metodológico da subjetividade, que o campo de uma antropologia dos partos e maternidades nasce no Brasil e começa a se consolidar dando visibilidade a outros tipos de violência contra as mulheres e fazendo críticas à dominação masculina, à ciência (seja às ciências da saúde ou as ciências sociais e sua forma de olhar partos e maternidades), e ao próprio movimento feminista e seu foco em determinados temas em detrimento de outros.

Este giro pode ser lido em uníssono às críticas que vem sendo feitas há anos pelas feministas e mulheres negras ao feminismo hegemônico. Podemos citar por exemplo bell hooks (2018) ao falar sobre aborto, Florita Telo (2019) sobre autonomia reprodutiva das mulheres em Angola, Robelle Damasceno (2020) sobre trajetórias reprodutivas de mulheres em situação de rua em Salvador - Bahia, Brasil, Giovanna De Carli Lopes sobre violência obstétrica e racismo institucional (trabalho em andamento), Emanuelle Góes (2010) sobre atenção à saúde e racismo, e mais especificamente sobre aborto e racismo, e ativistas e pesquisadoras que vem construindo reflexões sobre a experiência e/ou negação da maternidade das mulheres encarceradas.

Sem embargo, não podemos deixar de tecer algumas críticas a uma hegemonia branca, urbana e de camadas médias dentro do movimento pelo parto humanizado no Brasil, incluindo os contextos de pesquisas. Outro ponto que nos parece interessante para ser abordado 
antropologicamente é um crescente retorno à associação entre mulher e natureza, ou um apelo à natureza selvagem ou animal das mulheres nas descrições de suas experiências de parto e maternidade. Talvez haja aqui uma armadilha política e teórica, pois retrocede a um ponto superado pelas feministas, pelas teorias de gênero e pela própria antropologia.

Contudo, não há dúvidas de que todos esses pontos parecem ser, de alguma forma, uma possibilidade de oxigenação e refinamento da antropologia, da antropologia feminista e dos movimentos de mulheres e feministas a partir da consolidação do campo da antropologia sobre parto, nascimentos e maternidades, e da aproximação entre o movimento feminista e esses temas.

Segundo dados recentes da OMS, aproximadamente 810 mulheres morrem todos os dias por causas evitáveis relacionadas à gestação e ao parto no mundo e 94\% de todas essas mortes ocorrem em países ditos em desenvolvimento (WHO, 2019). Embora o Brasil não tenha alcançado a meta número 5 dos Objetivos de Desenvolvimento do Milênio (ODM), estabelecidos internacionalmente em 2000, que previa a redução até 2015 da mortalidade materna para 35 óbitos por 100 mil, houve uma redução, entre 1990 e 2015, de 143 para 62 óbitos maternos por 100 mil nascidos vivos (SZWARCWALD, 2014; BRASIL, 2018). Entretanto, com o desmonte da saúde pública, a taxa voltou a subir em 2016, para 64,4 (IPEA, 2019). Países considerados desenvolvidos apresentam taxa de mortalidade materna de 11 óbitos de mulheres por 100 mil nascidos vivos (WHO, 2019). Cerca de 92\% dos óbitos maternos poderiam ser evitados se os serviços de saúde oferecessem uma assistência obstétrica baseada em evidências (BRASIL, 2009). Além disso, a violência obstétrica, outro importante agravo à saúde, decorre exatamente disso: de uma assistência iatrogênica, obsoleta e não respeitosa, onde - assim como o parto - também é atravessada pelos marcadores de classe, raça, etnia e sexualidade.

Os homens também tem o seu papel definido na linha de produção da vida, papel esse que não contempla as transmasculinidades e outros arranjos familiares não heteronormativos. Essa normatividade perpassa todas as esferas do mundo social, estendendo-se também para o campo científico e de produção de conhecimento. Percebendo como estratégica a soma de ações como a ampliação legal dos direitos sexuais e reprodutivos das mulheres, o investimento em formação de pessoal e o avanço de movimentos feministas; e entendendo a importância de revisitar esses temas sob outra perspectiva para a construção de novas 
epistemologias que possam subsidiar mudanças efetivas, publicamos este número especial da Revista Cadernos de Gênero e Diversidade com a finalidade discutir o tema da reprodução, partos, maternidades e paternidades no Brasil e na América Latina, com contribuições de pesquisadoras e pesquisadores das áreas de ciências humanas e sociais e ciências da saúde, bem como ativistas e lideranças que atuam diretamente com a temática.

Vemos com grande entusiasmo a efervescência de estudos que discutem os temas das masculinidades, parentalidades e transparentalidades; temas cada vez mais consolidados e que demonstram a importância de pensar gênero de fato como uma relação social atravessada por relações de poder e que não dizem respeito apenas às mulheres (seja enquanto pesquisadoras, ativistas ou foco de análises). Esta publicação, para nós, é mais uma oportunidade de abrir espaços e discussões sobre estes temas, um movimento que de certo não finda aqui, carecendo de aprofundamentos.

A princípio organizaríamos um dossiê com um número limitado de artigos, todavia, percebemos a relevância e diversidade dos temas dos artigos propostos, e quão importante seria a divulgação de uma publicação mais robusta e que contribua para o campo de interface entre as ciências sociais e da saúde, com um viés feminista e interseccional, que discuta parto, maternidades e paternidades. Considerando isto, decidimos aprovar um número maior de trabalhos dentro de um número especial da revista. Tal número está organizado por eixos temáticos, a saber, "Parto e suas intersecções: classe, raça, etnia e sexualidade"; "Violência obstétrica"; "Paternidades e Transparentalidades"; "Processos de formação em obstetrícia, ciências e tecnologias"; "Direitos sexuais e reprodutivos e movimentos feministas".

Os textos abrigados nessa publicação versam sobre mulheres negras, racismo, resguardo de mulheres indígenas, biomedicina, violências, resistências, assistência obstétrica, cesariana, parto domiciliar, paternidade e guarda compartilhada, psicanálise e parto, formação de médicos obstetras, doulas e doulagem, feminismo, direitos reprodutivos e colonialidade, maternidade de mulheres em situação de cárcere, autonomia e medicalização dos corpos. Pontuamos, com um quê de tristeza, a falta de textos sobre transparentalidades, o que sem dúvida não significa que não existam bons trabalhos sobre o tema, e que nos coloca o desafio de pensar novas estratégias de diálogo com mais e outres pesquisadores e sujeites. 
A reprodução, o parto, as maternidades, e as paternidades precisam ser pensadas em suas dimensões sociais, culturais e políticas para além da perspectiva hegemônica branca-cis-hetero-normativa, que reside no imaginário social de forma universalizante, padronizada e biologizante.

É necessário garantir a autonomia das mulheres e das famílias e o acesso a um sistema de saúde humanizado, gratuito e de qualidade, que seja universal, mas não universalizante em suas práticas de cuidado; é necessário aprofundar o pensamento e a prática para um novo paradigma de formação, menos hierárquico e mais compartilhado, para que o cuidado não seja baseado em desigualdades de raça, gênero, etnia, geração, sexualidade, capacidade e religião, que acabam por produzir as mais diversas formas de violência, dentre elas a violência obstétrica. É preciso fortalecer os espaços de participação social que já existem e fomentar novas formas de participação popular nos processos de elaboração, execução e fiscalização das políticas públicas de saúde. É preciso também reconhecer e incluir outras e novas formas de maternidades e paternidades, a exemplo de maternidades e paternidades solos, negras, em contexto de comunidades tradicionais e LGBTQIA+. Dessa maneira, talvez seja possível construir experiências de nascer, crescer e viver mais justas socialmente e prazerosas.

Naiara Maria Santana NEVES

Giovanna De Carli LOPES

\section{Referências}

BADINTER, E. Um amor conquistado: o mito do amor materno. Rio de Janeiro: Nova Fronteira, 1985.

BRASIL. Secretaria de Vigilância em Saúde. Guia de vigilância epidemiológica do óbito materno. Brasília: Ministério da Saúde, 2009.

BRASIL. Secretaria de Vigilância em Saúde. Saúde Brasil 2017: uma análise da situação de saúde e os desafios para o alcance dos objetivos de desenvolvimento sustentável. Brasília: Ministério da Saúde, 2018.

CARNEIRO, Rosamaria Giatti \& RIBEIRO, Fernanda Bittencourt (organizadoras). Partos, maternidades e políticas do corpo. Civitas: 
Revista de Ciências Sociais/Programa de Pós-Graduação em Ciências sociais, Pontifícia Universidade Católica do Rio Grande do Sul. volume 15, número 2. Porto Alegre, 2015.

DAMASCENO, Belle. O custo do cuidado é sempre maior que o custo do reparo: Mulheres negras em situação de rua, maternidade e guerra às drogas. Revista Carta Capital, 04 de fevereiro de 2020.

GOES, Emanuelle Freitas; NASCIMENTO, ER do. Intersecção do racismo e do sexismo no âmbito da saúde sexual e reprodutiva. SEMINÁRIO INTERNACIONAL FAZENDO GÊNERO, DIÁSPORAS, DIVERSIDADES, DESLOCAMENTOS, v. 9, p. 1-8, 2010.

HOOKS, Bell. O feminismo é para todo mundo: políticas arrebatadoras. Rio de Janeiro: Rosa dos Tempos, 2018.

IPEA. Cadernos ODS - ODS 3: assegurar uma vida saudável e promover o bem-estar para todas e todos, em todas as idades. Brasília: Instituto de Pesquisa Econômica Aplicada, 2019.

NAVAZ, Liliana Suárez; CASTILLO, Rosalva Aída Hernández (Eds.). Descolonizando el feminismo: teorías y prácticas desde los márgenes. 2008 (1984).

ROHDEN, F. Uma Ciência da diferença: sexo e gênero na medicina da mulher. Rio de Janeiro: Editora Fiocruz, 2001.

RUBIN, Gayle. O Tráfico de mulheres: notas sobre a "economia política" do sexo. Recife, SOS Corpo,1993.

SEGATO, R. L. O Édipo brasileiro: a dupla negação de gênero e raça [Internet]. Universidade de Brasília: Departamento de Antropologia; 2006 [cited 2016 Jul 21].(Antropologia).

SENA, Ligia Moreiras. Ameaçada e sem voz, como num campo de concentração: a medicalização do parto como porta e palco para a violência obstétrica. 2016. 268 p. Tese de Doutorado. Universidade Federal de Santa Catarina, Centro de Ciências da Saúde, Programa de Pós-Graduação em Saúde Coletiva, Florianópolis, 2016. 
SZWARCWALD, C. L. et al. Estimação da razão de mortalidade materna no Brasil, 2008-2011. Cad. Saúde Pública, Rio de Janeiro, v. 30, supl. 1, p. S71-S83, 2014.

TELO, Florita Cuhanga António. Autonomia reprodutiva entre as Nkento Angolanas: narrativas e escolhas. 2019. 180 p. Tese de Doutorado. Universidade Federal da Bahia. Faculdade de Filosofia e Ciências Humanas (FFCH). Programa de Pós-Graduação em Estudos Interdisciplinares sobre Mulheres, Gênero e Feminismo (PPGNEIM), Salvador, 2019.

WHO. Trends in maternal mortality: 2000 to 2017: estimates by WHO, UNICEF, UNFPA, World Bank Group and the United Nations Population Division. Geneva: World Health Organization, 2019. 